\title{
Spectrum of Immunodeficiencies with Hodgkin's Disease
}

\author{
J. J. Twomey, A. H. Laughter, L. Rice, and R. Ford, Department of Medicine, \\ Veterans Administration Medical Center and Baylor College of Medicine, \\ Houston, Texas 77031; Department of Pathology, M. D. Anderson Hospital and \\ Tumor Institute, Houston, Texas 77030
}

\begin{abstract}
A B S T R A C T The role of six suppressor mechanisms upon $T$ and $B$ cell responses was studied on 17 untreated patients with Hodgkin's disease. Proliferative hyporesponsiveness to mitogen was greatly impaired in 8 of the 13 patients. 10 of these patients had an excessive degree of suppression by cells that adhered to foreign surfaces. Suppression by adherent cells correlated with impairment of proliferative responses and, in some instances, suppression was largely inhibited with indomethacin. Likewise, adherent cells suppressed immunoglobulin synthesis. A correlation was evident between suppression of $\mathrm{T}$ and $\mathrm{B}$ cell responses by adherent mononuclear leukocytes from individual patients. This suppression coincided with elevated percentages of monocytes in the patient mononuclear cell preparations. This excess of monocytes was not the result of a circulating monocytosis. The monocyte excess may have been acquired during isopyknic cell separation. A second form of suppression was observed in 5 of the 11 patients effected by a lymphocyte that neither adhered to glass wool nor required preactivation. It did not inhibit allogeneic lymphocytes, which contrasts with the suppressor abnormality of monocytoid cells.
\end{abstract}

\section{INTRODUCTION}

The level of immunologic competence is an important prognostic factor with Hodgkin's disease. It is generally believed that immunodeficiency lowers resistance to the neoplastic process. This probably contributes to the relatively poor prognosis and extensive disease involvement among elderly patients (1) who have experienced involution of the immune system. Immunodeficiency may predispose patients with Hodgkin's disease to second neoplasms (2) and to increased risk from infectious complications $(3,4)$.

Cell-mediated immunity is broadly impaired with Hodgkin's disease. The proliferative response to anti-

Received for publication 6 July 1979 and in revised form 14 April 1.980. gens $(5,6)$ and mitogens $(3,7)$, especially at suboptimal mitogen concentrations (8), is often impaired. Protein synthesis (9), mediator production (10), and cytotoxicity (11) by cultured lymphocytes are often subnormal. Immunodeficiency is expressed in vivo by cutaneous anergy $(12,13)$ and delayed homograft rejection (14). Nevertheless, in vitro abnormalities correlate poorly with clinical aspects of Hodgkin's disease (15). The basis for this apparent dichotomy has not been explained.

Suppression by a monocytoid cell contributes to the proliferative hyporesponsiveness of lymphocytes from patients with Hodgkin's disease (16-19). This abnormality is associated with an increase in the number of monocytes relative to lymphocytes in mononuclear leukocyte (MNL) ${ }^{1}$ preparations (17). It has been suggested that monocytes release excessive amounts of prostaglandins, thereby causing suppression (20). A second form of suppression, spontaneously effected by T lymphocytes, has been described with Hodgkin's disease $(19,21)$.

In contrast to other lymphomas (22), Hodgkin's disease is rarely found with primary immunoglobulin deficiency (23). Serum immunoglobulin levels (24) and antibody responses (25) are usually normal or elevated with Hodgkin's disease except when modified by intensive therapy (26). This is somewhat surprising because circulating $B$ cells are reduced as severely as $\mathrm{T}$ cells when patients become lymphopenic (15). Earlier studies have not reported impairment of humoral immune responses in culture.

It is apparent that a number of abnormalities contribute to the hyporesponsiveness of lymphocytes cultured from patients with Hodgkin's disease. Earlier studies did not address this complex issue comprehensively. It is not known whether the different suppressor abnormalities are interrelated or whether re-

\footnotetext{
'Abbreviations used in this paper: Ig, immunoglobulin; MLR, mixed leukocyte reaction; MNL, mononuclear leukocytes; NA-MNL, glass wool nonadherent mononuclear leukocytes; PHA, phytohemagglutinin.
} 
duced responses can be ascribed completely to suppression. Lymphopenia and functional impairment of lymphocytes may be coexistent but unrelated to adverse effects of Hodgkin's disease upon the lymphoid system. Furthermore, it has not been established whether lymphopenia is related to excessive suppression in vitro by monocytoid cells or T lymphocytes.

The present study represents an evaluation of the spectrum of cellular abnormalities that, individually, compromise lymphocyte responses with Hodgkin's disease. This experience illustrates the complexity of these changes and questions the relationship between clinical status and observations made in vitro. It seems reasonable to ascribe the derangements observed directly to Hodgkin's disease because our clinical material was restricted to relatively stable, untreated, young adult patients.

\section{METHODS}

Subjects. Studies were performed on 17 freshly diagnosed, untreated patients with histologically proven Hodgkin's disease. The median age was $24 \mathrm{yr}$ with an age range of $16-58$ yr. 12 were males and all but one were caucasian. 11 patients had clinical stage II disease and two patients each had stage I, III, or IV disease (27). Four patients had class B symptoms. 16 patients had nodular sclerotic tumors and one had a tumor of mixed cellularity (28). Normal blood was obtained from healthy subjects in the third age decade. A healthy subject was studied along with each patient.

Cell preparations. MNL were separated from heparinized blood by isopyknic flotation (29). Cells used to measure immunoglobulin (Ig) synthesis were washed four times in fetal calf serum (Reheis Co., Inc., Phoenix, Ariz.). Adherent cells were depleted by incubating MNL at $10-40 \times 10^{6}$ lymphocytes $/ 5 \mathrm{ml}$ in equilibrated syringes packed with $0.8 \mathrm{~g}$ glass wool (30). A one-way mixed leukocyte reaction (MLR) was achieved by exposing stimulating cells to 2,500 rad of $\mathrm{X}$-irradiation.

Lymphoproliferation culture system. Triplicate cultures were prepared in $0.4-\mathrm{ml}$ flat bottomed plastic microtiter plates (Linbro Chemical Company, Hamden, Conn.). Each culture contained $1 \times 10^{5}$ responding lymphocytes, 0.15 $\mathrm{ml}$ Eagle's minimum essential medium with 1-glutamine and antibiotics added (31), and $0.05 \mathrm{ml}$ fresh plasma from a healthy subject. Stimulation was with a $1: 1,000$ dilution of phytohemagglutinin (PHA)-P (Difco Laboratories, Detroit, Mich.), which is optimal in our system, or $1 \times 10^{5}$ and $4 \times 10^{5}$ lymphocytes in irradiated MNL preparations. We elected to use an optimal concentration of PHA because it gave the most consistent results with normal cells, and because we wanted to evaluate maximum responsiveness and the role of suppression under optical conditions by patient cells. Cultures were placed in a humidified incubator with $5 \% \mathrm{CO}_{2}$ and $95 \%$ air and were maintained at $37^{\circ} \mathrm{C}$. The culture period was $3 \mathrm{~d}$ in mitogen-stimulated cultures and $7 \mathrm{~d}$ in MLR cultures. To each culture, $2 \mu \mathrm{Ci}$ of $\left[{ }^{3} \mathrm{H}\right.$ thymidine (Schwarz/ Mann Div., Orangeburg, N. Y.; sp act $3 \mathrm{Ci} / \mathrm{mmol}$ ) was added for the last $24 \mathrm{~h}$ of incubation. Cultures were harvested using a multiple sample microprecipitator (Hiller, Madison, Wis.). The cells were then solubilized with $0.25 \mathrm{ml}$ NCS solubilizer (Amersham/Searle Corp., Arlington Heights, Ill.), $4 \mathrm{ml}$ scintillation fluid (31) was added, and incorporation measured in a liquid scintillation counter.
Ig synthesis culture system. Duplicate cultures were prepared in round-bottomed polystyrene tubes held upright and stationary in the same incubator as was used for lymphoproliferative tests. Each culture contained $1 \times 10^{6}$ lymphocytes, $0.9 \mathrm{ml}$ RPMI medium with antibiotics and $4 \mathrm{mN}$ 1-glutamine added, and $0.1 \mathrm{ml}$ fetal calf serum (Reheis Co., Inc.). Stimulation was with $10 \mu \mathrm{l}$ pokeweed mitogen (Gibco Laboratories, Grand Island Biological Co., Grand Island, $\mathrm{N}$. Y.) per culture. The incubation period was $14 \mathrm{~d}$. Supernates and sera were tested for IgG, IgA, and IgM content using Immunofluor kits (Bio-Rad Laboratories, Richmond, Calif.) and a fluorocolorimeter (American Instrument Co., Inc., Silver Spring, Md.). This assay can detect $75 \mathrm{ng}$ IgG, $105 \mathrm{ng} \operatorname{IgA}$, and $165 \mathrm{ng}$ IgM per $\mathrm{ml}$.

Tests for suppression. Suppression of lymphoproliferation by cells that adhere to foreign surfaces was tested by comparing responses to PHA by MNL and MNL depleted of adherent cells by incubation with glass wool. The effect of increasing the number of monocytes per unit culture volume was studied in the MLR using responding cells from healthy allogeneic donors and $4 \times 10^{5}$ and $1 \times 10^{5}$ stimulating MNLlymphocytes from the test donor. Indomethacin reversible suppression was measured in cultures stimulated with PHA to which no indomethacin and $1 \mu \mathrm{g} / \mathrm{ml}$ indomethacin (Merck Sharp \& Dohme Div., West Point, Pa.) was added. Spontaneous suppression by autologous lymphocytes was determined in MLR cultures where an additional $1 \times 10^{5}$ glass wool nonadherent irradiated cells from the donor under test were or were not added to the cultures. To test for concanavalin A activated T cell suppression (32), MLR cultures were prepared using MNL from healthy donor pairs that included $1 \times 10^{5}$ lymphocytes/culture from each donor; $1 \times 10^{5}$ irradiated glass wool nonadherent MNL (NA-MNL) from test donors that had been preincubated for $40 \mathrm{~h}(a)$ with $60 \mu \mathrm{g}$ concanavalin A (Calbiochem, La Jolla, Calif.) per $5 \times 10^{6}$ lymphocytes and $(b)$ without mitogen were added to paired cultures. The system of Broder et al. (33) was used to measure spontaneous suppression of Ig synthesis. 0.5 $\times 10^{6}$ MNL-lymphocytes from the test subject and a second healthy subject were co-cultured in $1 \mathrm{ml}$ of medium. $1 \times 10^{6}$ of the same cell preparations were cultured individually and average Ig values were recorded on the latter. In these suppressor tests, IgG, IgA, and IgM secretion per $10^{6}$ lymphocytes were added together. Suppression in all six test systems was expressed as a percentage derived from the formula $(1-a / b) \times 100$.

Statistics. Grouped values were expressed as mean \pm SEM. The significance of differences between groups was determined using the Wilcoxon signed rank test when comparing two treatment conditions of the same subject, and the Wilcoxon rank sum test when comparing the same treatment condition in different groups of subjects. Correlation coefficients were an expression of total variation about the means that can be explained by the regression; $P$ values were determined by a $t$ test.

\section{RESULTS}

Suppression of $T$ cell responses. Responses by MNL to PHA stimulation were significantly lower with Hodgkin's disease $(48,177 \pm 9,823 \mathrm{cpm})$ than with healthy donors $(135,590 \pm 9,146 \mathrm{cpm})(P<0.01)$ (Fig. 1). Adding indomethacin to the cultures increased these responses more with Hodgkin's disease $(50 \pm 6 \%)$ than with healthy subjects $(22 \pm 3 \%)(P<0.01)$. It is known that low concentrations of monocytes are 


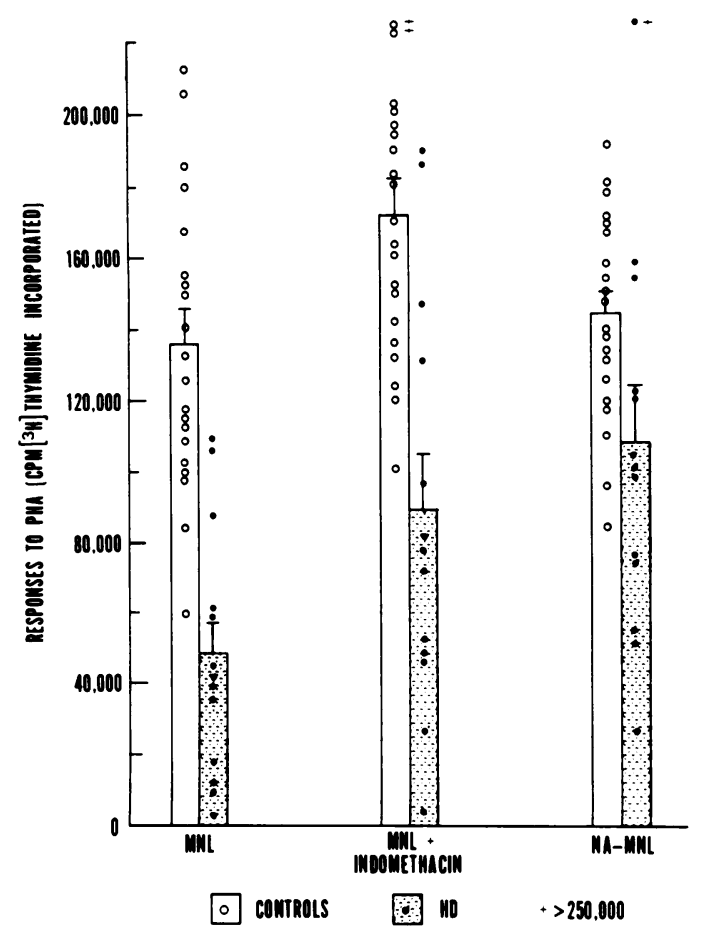

Figure 1 Responses to PHA by MNL, MNL plus indomethacin, and NA-MNL from 13 patients and 20 controls. HD, Hodgkin's disease.

needed for normal $\mathrm{T}$ cells to proliferate in response to PHA stimulation (34). The residual $3.9 \pm 1.4 \%$ monocytes after glass wool preincubation was sufficient in our culture system for responses by normal NA-MNL to approximate responses by $\mathrm{MNL}$ in paired cultures. Thus, $\mathrm{T}$ cell proliferation was not appreciably suppressed at the cell concentration employed by the monocyte content of normal MNL. In contrast, responses with NA-MNL were $54 \pm 8 \%$ higher than with MNL in paired cultures from patients with Hodgkin's disease $(P<0.01)$. Overall, adding indomethacin to cultures or removing cells that adhere to glass wool increased responses by patient cells to a comparable degree. Nevertheless, neither maneuver completely restored responses by the patient group to normal levels. Responses by lymphocytes from five patients were increased much more by adherent cell depletion than by adding indomethacin.

We have reported that high concentrations of a monocytoid cell, present in normal MNL preparations, spontaneously suppress lymphoproliferation (36). This suppression is evident with fewer MNL from patients with Hodgkin's disease (16). However, quantitative comparison is not possible with these earlier studies because the monocyte content of patient and normal MNL preparations was not standardized. In this study, MLR responses to $4 \times 10^{5}$ patient MNL-lymphocytes were $84 \pm 5 \%$ lower than responses to $1 \times 10^{5} \mathrm{MNL}$ lymphocytes. In similar studies, MLR responses were only lowered $27 \pm 8 \%$ by the additional number of normal irradiated MNL $(P<0.01)$.

When $1 \times 10^{5}$ irradiated NA-MNL from healthy donors were added with autologous responding MNL, the additional cells did not lower MLR responses by $>12 \%$ (Fig. 2). Lymphocytes from 5 of the 11 patients with untreated Hodgkin's disease suppressed to a greater degree MLR responses by autologous lymphocytes $(P<0.05)$ but did not suppress allogeneic lymphocytes. This donor specificity is in agreement with the report of Engleman et al. (21). The occurrence of suppression by autologous lymphocytes did not coincide with suppression by monocytoid cells shown in the preceding experiments $(P>0.2)$.

$T$ lymphocyte reactivity. Overall, proliferative responses to PHA by patient MNL were reduced and were lower than two standard deviations below the mean of 20 control experiments in 8 of the 13 patients $(P<0.01)$ (Fig. 1). Because responses on half of the patients remained subnormal after adding indomethacin to the cultures or prior removal of adherent cells, it is evident that factors other than monocytoid cell suppression often contribute to the impairment of $\mathrm{T}$ cell proliferation with Hodgkin's disease. Nevertheless, suppression by adherent cells did contribute significantly to impaired proliferation by patient MNL $(P<0.01)$. Abnormal $\mathrm{T}$ cell suppression did not account for low responses to PHA by NA-MNL from three patients. This indicates that there is an intrinsic impairment of $T$ cell proliferation in some patients with Hodgkin's disease that is distinct from suppressor abnormalities identified above.

Lymphopenia, defined as $<1,500$ lymphocytes $/ \mathrm{mm}^{3}$ of blood, was present in 7 of the 13 patients at the time of study. However, there was no apparent rela-

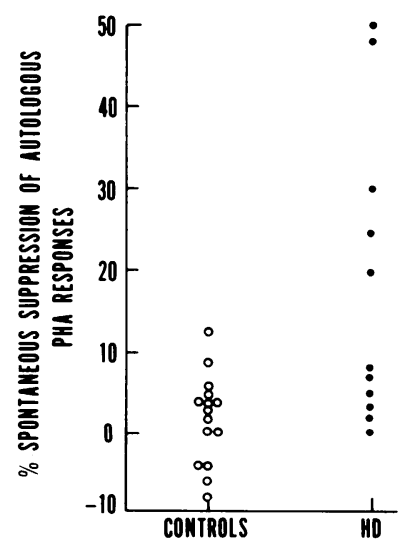

FIGURE 2 Spontaneous suppression of autologous MLR responses by $1 \times 10^{5} \mathrm{NA}-\mathrm{MNL}$ from 11 patients and 15 controls. $P<0.05$; HD, Hodgkin's disease. 
tionship between lymphopenia and impaired proliferative responsiveness of $\mathrm{T}$ cells removed from the suppressor influence of adherent cells by pretreatment with glass wool. This suggests that lymphopenia and intrinsic $T$ cell hyporesponsiveness to PHA are unrelated abnormalities with Hodgkin's disease.

The ability of concanavalin A to activate suppressor $T$ cells in NA-MNL was tested in the MLR on 10 patients with Hodgkin's disease and 16 control subjects. Suppression was $65 \pm 10 \%$ with Hodgkin's disease and $55 \pm 6 \%$ with healthy donors $(P>0.5)$. Thus, in contrast to $\mathrm{T}$ cell proliferation, the generation of mitogen-activated suppressor $\mathrm{T}$ cells remains intact with Hodgkin's disease, perhaps because proliferation is not necessary to activate these suppressor cells (32).

Plasma Ig levels and Ig synthesis in vitro. Plasma Ig levels were measured on the same collections of blood used for Ig synthesis by cultured MNL. Plasma IgG was slightly reduced in six patients; IgA was subnormal in patient 4 and Ig.M in patient 2 (Table I). Hyperimmunoglobulinemia was observed in six patients as has been reported (24).

We measured Ig synthesis by MNL from 15 patients with Hodgkin's disease and 26 control subjects in unstimulated cultures and in cultures stimulated with pokeweed mitogen. Responses by normal MNL were increased by an average of 19-fold by the presence of pokeweed mitogen. Responses to pokeweed mitogen by patient MNL were significantly reduced $(P<0.01)$. IgG, IgA, and IgM synthesis by patient MNL were $1,511 \pm 492,729 \pm 214$, and 1,956 $\pm 903 \mathrm{ng} \mathrm{Ig} / 10^{6}$ lymphocytes, respectively (Fig. 3). Responses by nor-

TABLE I

Plasma Ig Levels on 15 Patients with Hodgkin's Disease

\begin{tabular}{crrr}
\hline Patient & IgG & IgA & Ig.I \\
\hline & & mg \% & \\
1 & 487 & 124 & 119 \\
2 & 591 & 157 & 32 \\
3 & 615 & 158 & 84 \\
4 & 631 & 54 & 60 \\
5 & 723 & 189 & 104 \\
6 & 730 & 260 & 102 \\
7 & 840 & 203 & 110 \\
8 & 870 & 215 & 72 \\
9 & 880 & 272 & 249 \\
10 & 980 & 145 & 75 \\
11 & 992 & 215 & 78 \\
12 & 1,226 & 297 & 477 \\
13 & 1,720 & 337 & 116 \\
14 & 1,790 & 353 & 110 \\
15 & 2,190 & 377 & 185 \\
& & & \\
Normal range & $800-1,600$ & $120-230$ & $60-120$ \\
\hline
\end{tabular}

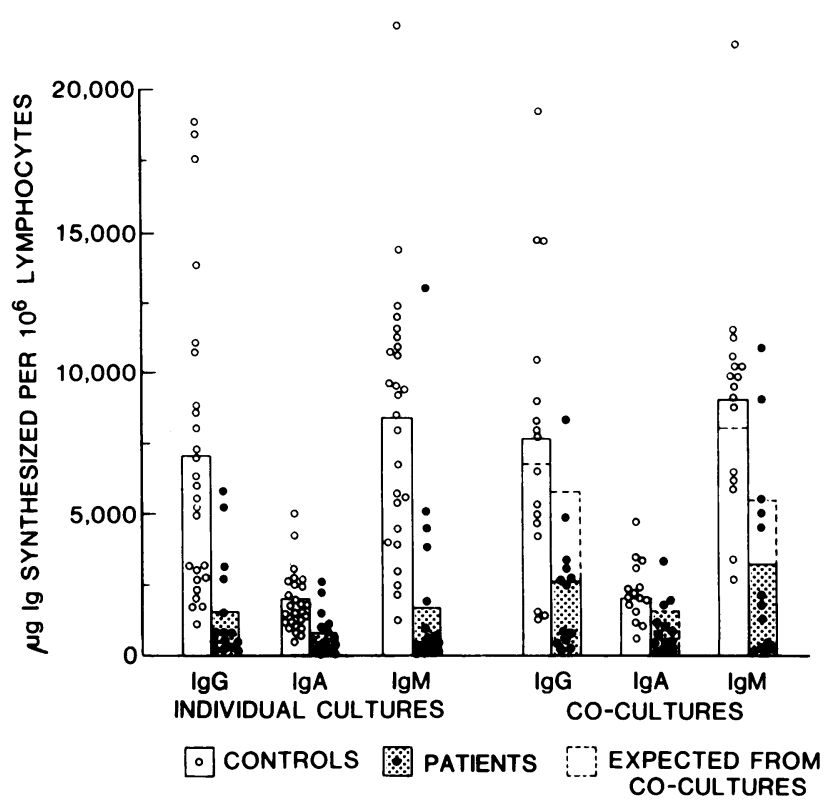

Figure 3 Pokeweed mitogen stimulated Ig synthesis by individual cultures of MNL from 15 patients and 26 controls. Also shown is suppression of Ig synthesis by co-cultures of (a) patients plus control MNL and (b) paired control MNL when compared with predicted values from the average of individual donor cultures.

mal MNL were $7,027 \pm 1,034,1,917 \pm 203$, and 8,392 $\pm 968 \mathrm{ng} \mathrm{Ig} / 10^{6}$ lymphocytes.

Ig synthesis in co-cultures of MNL from paired healthy subjects was, overall, slightly higher than predicted values determined from the average synthesis by cultures set up individually on each of the donors (Fig. 3). In contrast, mean Ig synthesis in co-cultures of patient and control MNL was only $52 \%$ of average synthesis by individual patient and control cultures $(P<0.05)$. Responses were suppressed $>35 \%$ in cocultures that included MNL from 8 of the 13 patients. This suppressor abnormality bore no relationship to the minor changes observed in plasma Ig levels.

The effect of removing adherent cells from patient MNL upon Ig synthesis was studied. Patient MNL responded poorly to pokeweed mitogen (Table II). Ig synthesis by NA-MNL from the same collection of patient blood was 7.9 times greater. Patient MNL suppressed Ig synthesis in co-culture with normal MNL by $34 \%$. Responses in co-cultures of patient NA-MNL plus control MNL were 6.4 times higher than in co-cultures of patient MNL plus control MNL. This suggests that glass wool preincubation removed an adherent cell from patient MNL that suppressed Ig synthesis.

The relationship between suppression of $T$ and $B$ cell responses. The preceeding studies showed that $\mathrm{T}$ cell proliferation and Ig synthesis were often suppressed 
TABLE II

Suppressor Effect of a Glass Wool Adherent MNL from a Patient with Hodgkin's Disease upon Ig Synthesis

\begin{tabular}{lrrr}
\hline \multicolumn{1}{c}{ Cell preparations } & \multicolumn{1}{c}{ IgG } & \multicolumn{1}{c}{ IgA } & \multicolumn{1}{c}{ IgM } \\
\hline & \multicolumn{3}{c}{$n g / g / l 0^{\circ}$ lymphocytes } \\
Patient MNL & 1,440 & 600 & 300 \\
Patient NA-M.NL & 5,000 & 5,100 & 7,150 \\
Control MNL & 5,300 & 2,170 & 3,600 \\
Patient MNL + control MNL & 2,200 & 950 & 1,350 \\
Patient NA-MNL + control MNL & 15,800 & 5,450 & 7,650 \\
\hline
\end{tabular}

Single donor cultures included $1 \times 10^{6}$ lymphocytes, and cocultures included $0.5 \times 10^{6}$ lymphocytes from each donor in $1 \mathrm{ml}$ medium.

by a glass wool adherent MNL. Because both suppressor abnormalities were identified with the same collections of blood, it was of interest to see if the frequency and magnitude of $\mathrm{T}$ and $\mathrm{B}$ cell suppression correlated with one another. Suppression of PHA responses was determined by comparing $\left[{ }^{3} \mathrm{H}\right]$ thymidine incorporation in paired MNL and NA-MNL cultures. Suppression of Ig synthesis was an expression of responses by co-cultures of patient and control MNL relative to predicted values from cultures set up individually on each donor. Both responses were clearly suppressed with MNL from eight patients, whereas neither response was suppressed with cells from four other patients (Fig. 4). There was a significant quantitative correlation between suppression of $\mathrm{T}$ and $\mathrm{B}$ cell responses by .MNL from individual patients $(P<0.01)$.

Monocyte content of MNL preparations and $T$ and $B$ cell suppression. An adherent cell that adheres to glass wool from many patient's with Hodgkin's disease causes abnormal suppression of proliferation by cul-

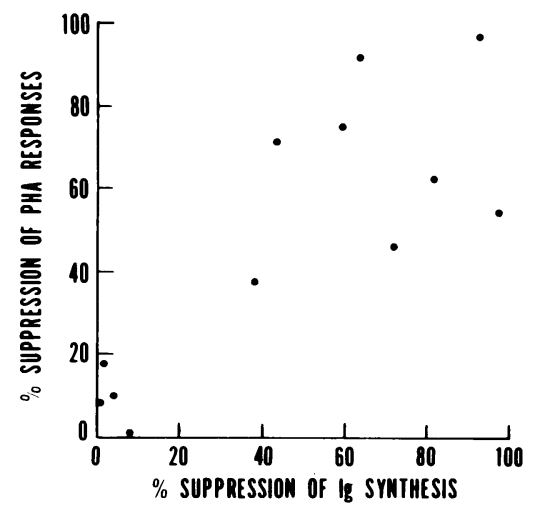

Figure 4 The relationship between (a) suppression of PHA responses by a cell that adheres to glass wool and $(b)$ suppression of $\mathrm{Ig}$ synthesis in co-cultures with normal cells by MNL from the same collections of blood from 12 patients. $r, 0.715 ; P<0.01$.

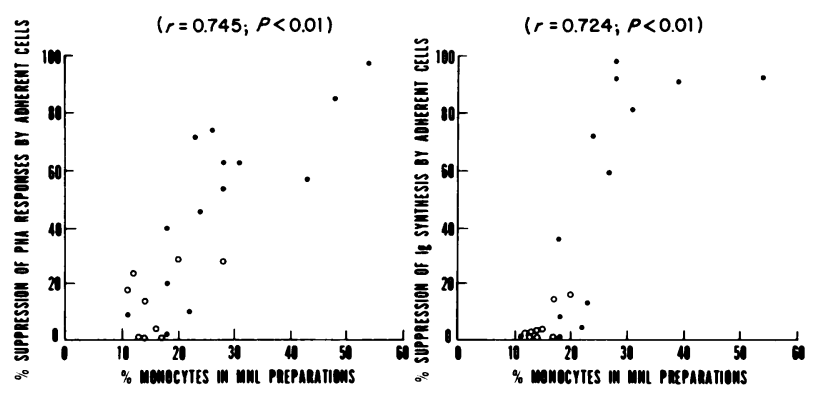

Figure 5 The relationship between MNL monocyte percentages and adherent cell suppression of PHA responses (left) and MNL suppression of Ig synthesis in co-cultures (right). 0 , patients; $\bigcirc$, controls.

tured $\mathrm{T}$ cells (16). A monocytoid cell probably contributes to this suppression. Therefore, we searched for a quantitative relationship between monocyte percentages and suppression of $\mathrm{T}$ and $\mathrm{B}$ cell responses by patient MNL preparations. Normal MNL usually contain 10-25\% monocytes. In contrast, MNL from 9 of the 19 patients included $>25 \%$ monocytes $(P<0.01)$. There was a significant relationship between elevated monocyte percentages and suppression of PHA responses or Ig synthesis by a glass wool adherent patient MNL $(P<0.01)$ (Fig. 5).

Suppression could be the result of elevated numbers of suppressor cells or increased suppressor activity by these cells. Suppressor activity correlated with monocyte concentrations and was generally evident in the presence of $>30 \%$ patient monocytes. Accordingly, MNL preparations with $>30 \%$ monocytes from three patients were tested for suppression of MLR responses by normal cells before and after diluting monocyte percentages down to $20 \%$ with lymphocytes. Responses were obviously increased when the content of patient monocytes was lowered to $20 \%$ (Table III).

TABLE III

MLR Responses by $1 \times 10^{5}$ Normal MNL-Lymphocytes to $4 \times 10^{5}$ Irradiated MNL-Lymphocytes from Three Patients with Elevated MNL Monocytes and Five Healthy Subjects

\begin{tabular}{lccc}
\hline & $\begin{array}{c}\text { Monocytes } \\
\text { in MNL }\end{array}$ & $\begin{array}{c}\text { Responses to } \\
4 \times 10^{5} \text { MNL- } \\
\text { lymphocytes }\end{array}$ & $\begin{array}{c}\text { Responses to } \\
4 \times 10^{5} \text { MNL- } \\
\text { lymphocytes, } \\
\text { monocytes } \\
\text { adjusted to 20\% }\end{array}$ \\
\hline Patient 1 & 48 & $c p m$ & $c p m$ \\
Patient 2 & 48 & 400 & 10,900 \\
Patient 3 & 33 & 1,600 & 42,100 \\
5controls & $<25$ & $40,100 \pm 9,300$ & 33,600 \\
\hline
\end{tabular}

Patient MNL were also tested after monocyte percentages were adjusted to $20 \%$. 
After dilution of monocytes, responses approximated responses to $4 \times 10^{5}$ normal MNL-lymphocytes. Occasionally, especially if ice-cold solutions and containers are used, normal MNL contain $>30 \%$ monocytes. These normal cells are capable of $\mathrm{T}$ cell suppression to a degree that is comparable with suppression with patient MNL. Unfortunately, it was not possible to perform quantitative studies on monocytoid cell suppression because preparations containing $>80 \%$ monocytes recovered by adherence to plastic did not consistently demonstrate suppressor activity.

Monocytes in cell preparations. The possibility that elevated monocyte percentages in patient MNL preparations reflected a circulating monocytosis was entertained. Monocyte percentages were determined on Wright Giemsa stained smears of whole blood and wet preparations of MNL from the same collections of blood. Normal whole blood contained $5.6 \pm 0.6 \%$ monocytes (Fig. 6). Although one patient had $14 \%$ monocytes, blood from the patient group did not contain significantly elevated numbers of monocytes. In contrast, monocyte percentages did differ significantly in MNL preparations from patient and control blood $(P<0.01)$. Monocyte percentages in 9 of the 19 patient MNL preparations exceeded two standard deviations above the normal mean. We considered the possibility that circulating lymphopenia could cause a relative excess of monocytes when harvesting MNL (17). However, it was not possible to demonstrate a significant relationship between lymphopenia in whole blood and elevated monocyte percentages in MNL harvested from the same collections of blood. This change in monocyte concentrations could be the result of excessive lymphocyte loss during cell processing. However, lymphocyte recovery was $58 \pm 5 \%$ after isopyknic flota-

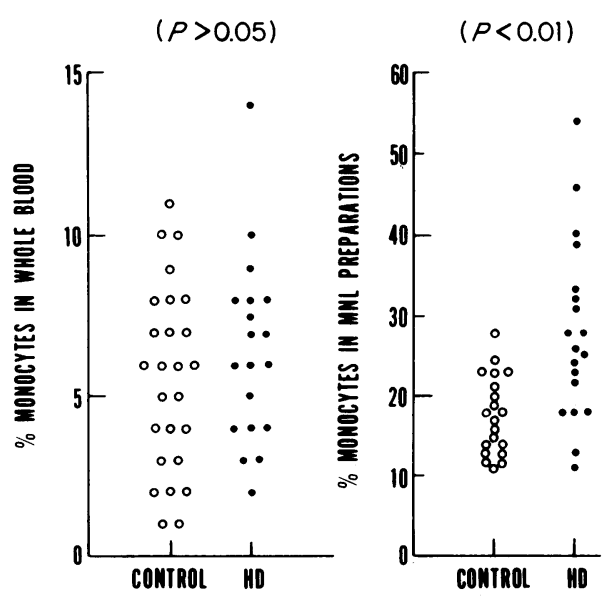

Figure 6 Whole blood (left) and MNL (right) monocyte percentages on patients and healthy subjects. HD, Hodgkin's disease. tion of patient blood and $55 \pm 4 \%$ with normal blood $(P>0.5)$. This suggests that functionally significant elevations in the monocyte content of MNL preparations from patients with Hodgkin's disease reflects a higher yield of monocytes from the cell separation procedure.

\section{DISCUSSION}

The present study shows that responses in culture by B cells as well as T cells are impaired with Hodgkin's disease. It is apparent that these impairments are caused by a complexity of mechanisms. In some instances, the capacity of $T$ cells to proliferate is intrinsically defective. Responses are also modulated through suppression by a cell that adheres to foreign surfaces or by a nonadherent $\mathrm{T}$ cell. The protocol was devised so that the relationship between these various abnormalities could be evaluated. It would appear that, with the exception of adherent cell suppression of $T$ and $B$ cell responses, immunologic abnormalities with Hodgkin's disease occur independently of one another.

Attention has recently focused upon excessive suppression with Hodgkin's disease. In this study, T cell proliferation was sometimes impaired after depleting adherent suppressor cells and in the absence of nonadherent $\mathrm{T}$ cell suppression. The increase in responses in the presence of indomethacin is minimal after depleting adherent cells. Thus, $\mathrm{T}$ cell responses can be intrinsically defective as well as excessively suppressed with Hodgkin's disease. Because the numbers of lymphocytes added per unit volume to cultures is standardized, the presence of lymphopenia in whole blood has no direct bearing upon the number of potentially responsive lymphocytes present in the cultures. We did not find a relationship between the severity of lymphopenia in blood and proliferative capabilities of patient lymphocytes removed from the influence of adherent suppressor cells. This suggests that circulating lymphopenia and reduced $\mathrm{T}$ cell proliferation in vitro occur independently of one another.

In contrast to the poor mitogen-stimulated proliferative responses, mitogen-activated suppression by $\mathrm{T}$ cells was normal with Hodgkin's disease. Helper T cells are required for Ig responses to pokeweed mitogen (35). When adherent cells were depleted, Ig responses by patient lymphocytes to pokeweed mitogen were appreciable. These observations suggest that suppressor and helper activities are less impaired than other $\mathrm{T}$ cell functions related to the effector apparatus. The capacity of B cells to secrete Ig is probably normal.

A cell present in normal MNL preparations that adheres to foreign surfaces suppresses both $\mathrm{T}(32,36$, $37)$ and B cell $(38,39)$ responses. The level of suppres- 
sion correlates with the monocyte content of the MNL preparation. The suppressor cell is either a monocyte or another non-T cell that also adheres to glass wool. Suppression is mediated through two distinct mechanisms (32), one of which involves the release of prostaglandins (40) and is inhibited by indomethacin (37). The second mechanism involves the release of a labile, low molecular weight mediator ${ }^{2}$ that is not inhibited by indomethacin (32).

Goodwin et al. (20) reported that indomethacinreversible suppression of PHA responses and prostaglandin $E_{2}$ production by a glass adherent $\mathrm{MNL}$ is elevated with Hodgkin's disease. The present work substantiates this observation. However, the magnitude of total suppression by adherent cells did not correlate with indomethacin-reversible suppression $(P<0.05)$. In five instances, adherent cell removal ablated suppression more effectively than adding indomethacin to MNL cultures. Perhaps monocytoid cells from these patients were also excessively suppressive through a second prostaglandin-independent mechanism analogous to their normal counterparts. Overall, suppression by adherent MNL was a significant factor in the impairment of $\mathrm{T}$ cell proliferation with Hodgkin's disease $(P<0.01)$. The quantitative relationship demonstrated between monocytoid cell suppression of $\mathrm{T}$ and $\mathrm{B}$ cell responses $(P<0.01)$ suggests that the same abnormality is responsible for both.

The question arises as to whether this excessive monocytoid cell suppression is a quantitative and/or qualitative abnormality. Certainly the monocyte content of MNL preparations is often elevated with Hodgkin's disease (17). We demonstrated a quantitative relationship between monocyte percentages in MNL preparations and monocytoid cell suppression of $\mathrm{T}$ and B cell responses with this disease $(P<0.01)$. Furthermore, when the monocyte content of normal MNL exceeded $30 \%$, a similar level of suppression to that seen with Hodgkin's disease was observed. Conversely, when the monocyte content of patient MNL was adjusted downward to a normal $20 \%$, suppression was no greater than with control MNL. Thus, elevated numbers of monocytes is quantitatively related to increased suppression with this neoplasm. It is also possible that this suppressor system is qualitatively abnormal. This possibility is supported by a preliminary report that prostaglandin release by monocyte concentrates is elevated with Hodgkin's disease (41). It is also possible that lymphocytes from these patients are excessively sensitive to monocytoid cell suppression as is the case with elderly individuals (42).

${ }^{2}$ Laughter, A. H., L. Rice, and J. J. Twomey. 1980. Supression of lymphocyte responses by a labile mediator released by adherent leukocytes. Manuscript submitted for publication.
The basis for the elevated monocyte content of MNL from patients with Hodgkin's disease is unclear. It is not caused by a circulating monocytosis as is the case with sarcoidosis (43). We found no evidence that it reflected a distortion in the number of blood monocytes relative to lymphocytes caused by lymphopenia. Lymphocyte loss during isopyknic flotation was not excessive. Therefore, it appears that monocyte recovery after isopyknic separation is elevated. Reduced adherence to foreign surfaces (44) could account for this high yield.

Responses in the MLR are also excessively suppressed by T cells from over $50 \%$ of the patients with Hodgkin's disease but only $2 \%$ of healthy subjects (21). The present study shows that this is a disease rather than a therapy-related abnormality and bears no apparent relationship to monocytoid cell suppression. The significance of this abnormality is uncertain because it bore no apparent relationship to impaired $\mathrm{T}$ cell proliferation. This form of suppression is effected by a T lymphocyte that does not adhere to glass wool and does not inhibit allogeneic lymphocytes, which clearly distinguishes it from monocytoid cell suppression. It is now apparent that discrete subpopulations of $\mathrm{T}$ cells have suppressor capabilities (45). Distortion of $\mathrm{T}$ cell subpopulations can greatly alter immune reactivity through suppressor abnormalities (46). Perhaps normal $\mathrm{T}$ cell suppression is sometimes exaggerated with Hodgkin's disease through distortion of the relative numbers of suppressor and other $T$ lymphocytes.

Clinical parameters correlate poorly with responses by cultured leukocytes from patients with Hodgkin's disease (15). This is well illustrated herein in that $\mathrm{Ig}$ synthesis by patient MNL was often severely impaired, although humoral immunodeficiency is not a feature of untreated Hodgkin's disease $(24,25)$. The fact that this deficit in vitro may be unique to MNL preparations is suggested by the report of Longmire et al. (47) that Ig synthesis by cultured spleen cells is elevated with this disease. This apparent dichotomy probably reflects the high monocyte percentages in MNL preparations that are not present in whole blood or perhaps in spleen cell suspensions. Thus, monocytoid cell suppression may be less active in vivo than in culture.

\section{ACKNOWLEDGMENTS}

We are grateful to Mrs. Sara Lazar for technical assistance.

This work was supported by National Cancer Institute grants CA 16108 and CA 16672 awarded by the National Institutes of Health.

\section{REFERENCES}

1. Kaplan, H. S., and P. A. Bissinger. 1973. Survival and relapse rates in Hodgkin's disease: stanford experience 1961-1971. Natl. Cancer Inst. Monogr. 36: 487-496. 
2. Hall, T. C. 1978. Leukemia in patients treated for Hodgkin's disease. N. Engl. J. Med. 298: 853-854.

3. Casazza, A. R., C. P. Duval, and P. P. Carbone. 1966. Infection in lymphoma.J. Am. Med. Assoc. 197: 118-124.

4. Feld, R., G. P. Bodye, V. Rodriguez, and M. Luna. 1974. Causes of death in patients with malignant lymphoma. Am. J. Med. Sci. 268: 97-106.

5. Hersh, E. M., and J. J. Oppenheim. 1965. Impaired in vitro lymphocyte transformation with Hodgkin's disease. N. Engl. J. Med. 273: 1006-1012.

6. Twomey, J. J., A. H. Laughter, S. Lazar, and C. C. Douglass. 1976. Reactivity of lymphocytes from primary neoplasms of lymphoid tissues. Cancer (Phila.). 38: $740-747$.

7. Aisenberg, A. C. 1965. Quantitative estimation of reactivity of normal and Hodgkin's disease lymphocytes with thymidine-2 $2{ }^{14} \mathrm{C}$. Nature (Lond.). 205: 1233-1235.

8. Faguet, G. B. 1975. Quantitation of immunocompetence in Hodgkin's disease. J. Clin. Invest. 56: 951-957.

9. Levy, R., and H. S. Kaplan. 1974. Impaired lymphocyte function in untreated Hodgkin's disease. N. Engl.J. Med. 290: $181-186$.

10. Churchill, W. H., R. R. Rocklin, W. C. Maloney, and J. R. David. 1973. In vitro evidence of normal lymphocyte function in some patients with Hodgkin's disease and negative delayed cutaneous hypersensitivity. Natl. Cancer Inst. Monogr. 36: 99-106.

11. Holm, G., P. Perlman, and B. Johansson. 1967. Impaired phytohemagglutinin induced cytotoxic action of lymphocytes from patients with Hodgkin's disease or chronic lymphocytic leukemia. Clin. Exp. Immunol. 2: 351-360.

12. Young, R. C., M. P. Corder, H. A. Haynes, and V. T. Devita. 1972. Delayed hypersensitivity in Hodgkin's disease. Am. J. Med. 52: 63-72.

13. Eltringham, J. R., and H. S. Kaplan. 1975. Immunodeficiency in Hodgkin's disease. Birth Defects Orig. Artic. Ser. 11: 278-288.

14. Miller, D. G., and J. G. Lizardo. 1961. Homologous and heterologous skin transplantation in patients with lymphomatous disease. J. Natl. Cancer Inst. 26: 569-583.

15. Twomey, J. J., R. A. Good, and D. C. Chase. 1978. Immunologic changes with Hodgkin's disease. In The Immunopathology of Lymphoreticular Neoplasms. J. J. Twomey and R. A. Good, editors. Plenum Publishing Corporation, New York. 585-608.

16. Twomey, J. J., A. H. Laughter, S. Farrow, and C. C. Douglass. 1975. Hodgkin's disease: an immunodepleting and immunosuppressive disorder. J. Clin. Invest. 56: 467-475.

17. Schechter, G. P., and Soehnlen, F. 1978. Monocytemediated inhibition of lymphocyte blastogenesis in Hodgkin's disease. Blood. 52: 261-271.

18. Sibbitt, W. L., A. D. Bankhurst, and R. C. Williams, Jr. 1978. Studies of cell subpopulations mediating mitogen hyporesponsiveness in patients with Hodgkin's disease. J. Clin. Invest. 61: 55-63.

19. Hillinger, S. M., and Herzig, G. P. 1978. Impaired cellmediated immunity in Hodgkin's disease and mediated by suppressor lymphocytes and monocytes. J. Clin. Invest. 61: 1620-1627.

20. Goodwin, J. G., R. P. Messner, A. D. Bankhurst, G. T. Peake, G. T. Saiki, and R. C. Williams, Jr. 1977. Prostaglandin producing suppressor cells in Hodgkin's disease. N. Engl. J. Med. 297: 963-968.

21. Engleman, E. G., C. Benike, R. T. Hoppe, and H. S. Kaplan. 1979. Suppressor cells of the mixed lymphocyte reaction in patients with Hodgkin's disease. Transplant. Proc. In press.
22. Spector, B. D., G. S. Perry, III, R. A. Good, and J. H. Kersey. 1978. Immunodeficiency diseases and malignancy. In The Immunopathology of Lymphoreticular Neoplasms. J. J. Twomey and R. A. Good, editors. Plenum Publishing Corporation, New York. 203-222.

23. Hoffbrand, B. I. 1964. Hodgkin's disease and hypogammaglobulinemia: a rare association. Br. Med. J. 1: 1156-1158.

24. Wagener, D. J., Th., P. J. J. van Mienster, and C. Haanen. 1976. The immunoglobulins in Hodgkin's disease. Eur. J. Cancer. 12: 683-688.

25. Weitzman, S. A., A. C. Aisenberg, and G. R. Silber. 1977. Impaired humoral immunity in treated Hodgkin's disease. N. Engl. J. Med. 297: 245-248.

26. Silber, G. R., S. A. Weitzman, A. C. Aisenberg, H. J. Weinstein, and G. Schiffman. 1978. Impaired antibody response after treatment for Hodgkin's disease. N. Engl. J. Med. 299: 442-447.

27. Carbone, P. P., H. S. Kaplan, K. Musshoff, D. W. Smithers, and M. Tubiana. 1971. Report of the committee on Hodgkin's disease staging classification. Cancer Res. 31: $1860-1861$.

28. Lukes, R. J., L. F. Craver, T. C. Hall, H. Rappaport, and P. Rubin. 1961. Part I. Report of the Nomenclature Committee. Cancer Res. 26: 1311.

29. Boyum, A. 1968. Isolation of mononuclear cells and granulocytes from human blood. Scand. J. Clin. Lab. Invest. Suppl. 21(Suppl. 97): 77-89.

30. Folch, H., and B. H. Waxman. 1974. The splenic suppressor cell. I. Activity of thymus dependent adherent cells: changes with age and stress. J. Immunol. 113: $127-139$.

31. Twomey, J. J., O. Sharkey, Jr., J. A. Brown, A. H. Laughter, and P. H. Jordon, Jr. 1970. Cellular requirements for the mitotic response in allogeneic mixed leukocyte cultures. J. Immunol. 104: 845-853.

32. Rice, L., A. H. Laughter, and J. J. Twomey. 1979. Three suppressor systems in human blood that modulate lymphoproliferation. J. Immunol. 122: 991-996.

33. Broder, S., R. Humphrey, M. Drum, M. Blackman, B Meade, C. Goldman, W. Strober, and T. Waldmann. 1978. Impaired synthesis of polyclonal (non-paraprotein) immunoglobulins by circulating lymphocytes from patients with multiple myeloma. N. Engl. J. Med. 293: $887-892$.

34. Rosenstreich, D. L., J. J. Farrar, and S. Dougherty. 1976. Absolute macrophage dependency of T lymphocyte activation by mitogens. J. Immunol. 116: 131-139.

35. Kirchner, H., G. Tosato, R. M. Blaese, S. Broder, and I. T. McGrath. 1979. Polyclonal immunoglobulin secretion by human B lymphocytes exposed to Epstein-Barr virus in vitro. J. Immunol. 122: 1310-1313.

36. Laughter, A. H., and J. J. Twomey. 1977. Suppression of lymphoproliferation by high concentrations of normal human mononuclear leukocytes. J. Immunol. 119: $173-179$

37. Goodwin, J. S., A. D. Bankhurst, and R. P. Messner. 1977. Suppression of human $\mathrm{T}$ cell mitogenesis by prostaglandin. J. Exp. Med. 146: 1719-1733.

38. Knapp, W., and G. Baumgartner. 1978. Monocyte mediated suppression of human B-lymphocyte differentiation in vitro. J. Immunol. 121: 1177-1183.

39. Laughter, A. H., M. D. Lidsky, and J. J. Twomey. 1979. Suppression of immunoglobulin synthesis by monocytes in health and in patients with systemic lupus erythematosus. Clin. Immunol. Immunopath. 14: 435-440.

40. Goldnye, M. E. 1977. Prostaglandins and the modula- 
tion of immunological responses. Int. J. Dermatol. 16: $701-712$

41. Bockman, R. S. 1979. Prostaglandins and T-lymphocyte colonies in Hodgkin's disease. Clin. Res. 27: 381A (Abstr.)

42. Goodwin, J. S., and R. P. Messner. 1979. Sensitivity of lvmphocvtes to prostaglandin $\mathrm{E}_{\text {, }}$, increases in subjects over age 70. J. Clin. Invest. 64: 434-439.

43. Goodwin, J. S., R. DeHoratius, H. Israel, G. T. Peake, and R. P. Messner. 1979. Suppressor cell function in sarcoidosis. Ann. Intern. Med. 90: 169-173.

44. Blaese, R. M., J. J. Oppenheim, R. C. Seegers, and T. A Waldmann. 1972. Lymphocyte-macrophage interaction in antigen in vitro lymphocyte transformation in patients with Wiskott-Aldrich syndrome and other diseases with anergy. Cell. Immunol. 4: 228-242.

45. Moretta, L., S. R. Webb, C. E. Grossi, P. M. Lydyard, and M. D. Cooper. 1977. Functional analysis of two human T cell subpopulations: help and suppression of $B$ cell responses by $\mathrm{T}$ cells bearing receptors for $\operatorname{IgM}$ and IgG. J. Exp. Med. 146: 184-200.

46. Reinherz, E. L., A. Rubenstein, R. S. Geha, A. J. Strelkauskas, F. S. Rosen, and S. F. Schlossman. 1979. Abnormalities of immunoregulatory $\mathrm{T}$ cells in disorders of immune function. N. Engl. J. Med. 301: 1018-1022.

47. Longmire, R. L., R. Mc.Millan, R. Yelonsky, S. Armstrong, J. E. Lang, and C. G. Graddock. 1973. In vitro splenic Ig synthesis in Hodgkin's disease. N. Engl. J. Med. 289: $763-767$ 